\title{
Digital technologies in foreign language learning
}

Olga Baryshnikova ${ }^{*}$, Alexander Kostenko, and Stanislav Voskoboynikov

Don State Technical University, 344000, Rostov-on-Don, Russia

\begin{abstract}
This article will examine the digitalization of education, its effectiveness, pros and cons. In addition, digital technologies will be able to affect the performance and motivation of students. Possible educational potential of digital technologies in teaching of foreign languages, recommendations on methods for integrating digital technologies into the educational process for work and independent work organizing of students and pupils are some of their advantages. Digital education offers new learning opportunities as student engagement in an interactive digital environment and educators use hybrid personalized learning courses, innovative, engaging learnng strategies. Looking at student success in the modern conditions they are required to be not only thoughtful digital content users, but also effective digital media creators are able to collaborate their skills and share ideas through dynamic storytelling, data visualization. The article describes the works by both Russian and foreign authors devoted to the advantages and some risks arising in society as a result of the digitalization in education. Advantages and disadvantages of digital education are clearly have been shown in the article. As the latest and most advanced technology is very expensive, at presents digitalization has both defenders and opponents of this phenomenon. It remembers about tremendous expenses on the newest digital tools and software. The final idea of this article is to create a flexible learning environment that encourages innovation.
\end{abstract}

\section{Introduction}

Digital technologies are widely used at present even in training of future translators. The educational process is experiencing a period of transition from traditional synchronous methods of learning which take place in the classroom to asynchronous ones that can be applied at any place and / or time and can be presented as distance or e-learning [1].

The purpose of this article will describe the need for digitalization of education, and show in detail its advantages and disadvantages. The main digital tools and devices for usage of distance learning in the modern world have been analyzed to understand the convenience and the nearest prospects of this technology in the future. Digitalization of education is a modern direction to reform and modernize the global educational system. The newest sources of important information such as text, sound, video and other data have

\footnotetext{
*Corresponding author: sunshine_lera@mail.ru
} 
been put into digital languages. Especially digitalization has become necessary measure in condition of global pandemic when the educational process must be continued. The teachers must be more creative and the students must be more independent. Technology will help to achieve good educational results in two main ways: solving physical problems and shifting attention from preserving knowledge and maintaining student concentration. These methods should be investigated in their relationship to both the student and the teacher, in order to identify their value and effect in the educational environment.

\section{Materials and Methods}

\subsection{Interactive systems for teaching}

A foreign language is an academic subject where a special condition has been created for students, which determines the levels of different digital teaching aids for new tasks of a foreign language teaching. Digital teaching purposes are interactive systems, working simultaneously with animated computer graphics, sound, video frames, texts and images. The user- the student is directly influenced through various information programs, courses and tools, where the user play an active role, obtain additional knowledge independently.

Multimedia lesson is an educational lesson using digital technologies, various programs and technical means for effective impact on the learner. It demands the best tools and devices, software with the highest quality.

Multimedia presentations are the next effective method of teaching introduced into the educational process for their usage; the main components are a computer and a projector. Presentations can be carried out both synchronously and asynchronously, i.e. be prerecorded. They show clearly the level of knowledge and technical skills, creative approaches of both sides: a teacher and a student.

Of course, the way in which presentations are included in a lesson depends on many factors: knowledge level of students, technical possibilities in classroom, the content of the lesson and its objectives. The methods of presentation depend on purposes: learning of new material; consolidation of a new topic; checking of independent home task.

Electronic testing is an automated device for monitoring and checking knowledge by a teacher or a self-monitoring tool that provides an oral and writing visual control of the results. It demands high qualification and professional skills from teachers first of all.

The basic resource should be the resource of the European Commission on Foreign Ownership languages (CEFR), which allows you to determine the level of language proficiency according to the scale used in the framework of the Bologna Convention. It provides recommendations and instructions for a language learning to achieve a certain level, according to the test results. It is possible to get original Certificates after some test graduation.

A multimedia Internet resource presents interactive and entertaining information (text, animation, graphics, sound and video).

For teaching general and business English at higher schools, it is comfortable to use textbooks with electronic applications on the Internet:

a) Speak out (A1-B2): Active Book - an electronic version of a book for students with additional materials, where you can watch videos and listen to audio materials with exercises; My Speakout Lab component makes it possible to carry out personalized training and evaluate the results online, where there are options for instant feedback, an automatic progress diary, audio and video files, a testing program that allows you to track the final test result. 
b) Business Result (A1 -B2) (OUP): an interactive workbook on CD is a digital resource for independent work of students on grammar, vocabulary and listening.

c) Market Leader (A1-B2) (Pearson): an interactive workbook on CD -ROM with exercises for grammar, vocabulary, listening. The online component MyEnglishLab provides additional practice.

d) MyGrammarLab (A2-B2): the online component includes a Diagnostic Test for each level, video tutorials explaining grammar rules; tasks and exercises for each section with automatic checking and error analysis; Progress Tests and Exit Tests after each section; tools for practicing pronunciation, listening and checking your answers to exercises in a printed book; some exercises to prepare for international exams.

\subsection{Digital applications}

For developing student self-organization skills are the most relevant soft skills today:

1) EasyBib - this resource can be used when writing research papers both in foreign languages and in Russian. It allows you to form automatically bibliographic lists for scientific papers with citation styles like MLA, APA and Chicago / Turban.

2) Milk is a free resource helps you to create an online timetable with deadlines for completing certain tasks, draw up schedules, etc. It can be used from various platforms, such as Gmail, Twitter, iPad, iPhone, Android.

3) Survey monkey is an Internet resource used by both students and teachers to create all kinds of tests, questionnaires, quizzes. It is comfortable both for performing various tasks using the technology of task-based learning and content-language integrated learning, and for receiving feedback from students or a teacher. A resource called Classmarker is similar to it.

4) Bubbl.us is the next Internet resource for creating so-called mind maps online. Such "memory cards" help to organize the necessary information for the most rapid study, memorization and repetition. In classroom they are taken at the beginning of the lesson by both students and teachers to repeat and create an interesting introduction to a new topic.

5) Create-a-Graph - this resource allows you to make various graphical forms of information representation, such like graphs, tables, charts, etc. [2]

\subsection{Risks of education digitalization}

These works by both Russian and foreign authors are devoted to the risks arising in society as a result of the digitalization of education. It is believed that the widespread interaction of digital technologies in the field of education will lead to some consequences, which can be conditionally divided into the following groups:

- Psychological (loss of basic cognitive competencies, increased requirements for knowledge, potential

- Growth of conflict in the educational environment, the dispersion of the subjectivity of students).

- Social (increased social atomization, alienation both within the student community and between students and teachers, digital totalitarianism, ridicule and bullying).

- Risks to the health of students (visual impairment, development of hypodynamia, depressive states).

- Risks of an existential and ethical order (virtualization of life, development of digital addictions, regulatory crisis). 
- Information risks (violation of privacy, ignoring copyright, digital inequality, cyber fraud). [3]

Below is a map of digitalization risks in scheme 1. It shows the risks that make up the structure of the theoretical research model and the risks identified during the interview. It is important that relationships can be established between many components of the map. For example, the growth of social exclusion between students, their parents and teachers can potentially lead to a series of conflicts among participants in the educational process.

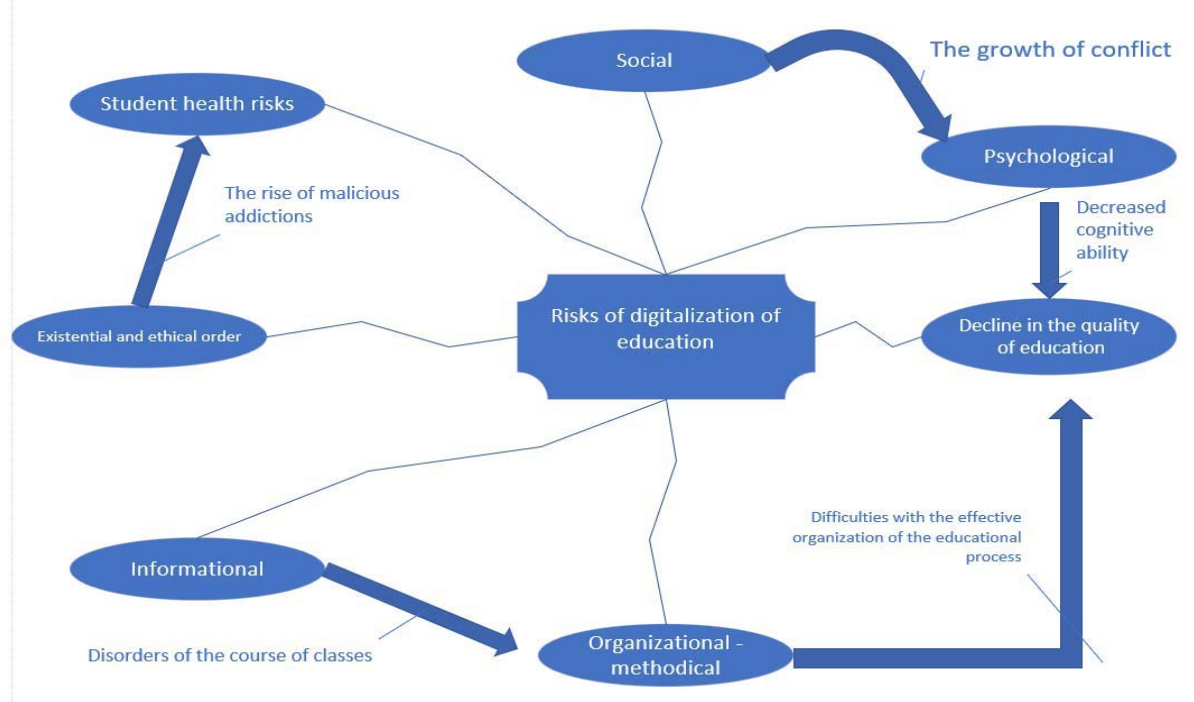

Fig. 1. Mental map of the risks of digitalization of education

\section{Results}

\subsection{Advantages}

The online learning system, with its wide range of capabilities and resources, can be personalized in many ways. This is the best way to create an ideal learning environment that meets the needs of each student. [4]

Table 1. Advantages of digital education

\begin{tabular}{|c|c|}
\hline Advantage & Description \\
\hline Effectiveness & $\begin{array}{c}\text { Online learning offers educators an effective way of } \\
\text { delivering lessons to students. This way has a number } \\
\text { of tools like videos, PDFs, podcasts, and teachers can } \\
\text { use all of these tools as part of their lesson plans. The } \\
\text { teacher can expand the lesson plan with online } \\
\text { resources; as a result, teachers can become more } \\
\text { educators that are effective. }\end{array}$ \\
\hline
\end{tabular}




\begin{tabular}{|c|c|}
\hline $\begin{array}{c}\text { Availability of time and } \\
\text { place }\end{array}$ & $\begin{array}{l}\text { Another advantage of online education is that students } \\
\text { attend classes from anywhere in the world of their } \\
\text { choice. It also helps schools reach a wider audience of } \\
\text { students, rather than being limited by geographic } \\
\text { boundaries. Online lectures can be recorded, archived } \\
\text { and used for future reference. This allows students to } \\
\text { access study material at any time. } \\
\text { Thus, online learning offers students the availability of } \\
\text { time and place in education. }\end{array}$ \\
\hline Affordability & $\begin{array}{l}\text { Another benefit of online learning is the economic } \\
\text { benefit. Online education is significantly more } \\
\text { affordable compared to physical education. This is } \\
\text { because online education does not require the cost of } \\
\text { student transport, student meals, and most importantly, } \\
\text { real estate. In addition, the entire course or teaching } \\
\text { material is available online, eliminating the waste of } \\
\text { paper, which is more affordable and beneficial to the } \\
\text { environment. }\end{array}$ \\
\hline $\begin{array}{l}\text { Improving student } \\
\text { attendance }\end{array}$ & $\begin{array}{c}\text { With online classrooms, because classes are held at } \\
\text { home or anywhere they choose, students will be less } \\
\text { likely to miss classes }\end{array}$ \\
\hline $\begin{array}{l}\text { Suitable for a variety of } \\
\text { learning styles }\end{array}$ & $\begin{array}{c}\text { Each student has a different learning path and } \\
\text { individual learning style. Some students are visual } \\
\text { learners, while some students prefer to learn through } \\
\text { audio. Likewise, some students thrive in the classroom, } \\
\text { while others are single students who are distracted by } \\
\text { large groups. }\end{array}$ \\
\hline
\end{tabular}

The online learning system, with its wide range of capabilities and resources, can be personalized in many ways. This is the best way to create an ideal learning environment that meets the needs of each $\mathrm{s}$

Thus, students are simply using technology instead of drawing from this knowledge. Using applied science to educate properly is good, but it is just a matter of time before turning it into an active skill set.

Full use of computers breeds bad study habits. Many students continue to browse websites looking for the shortest way to solve math problems, instead of solving them in the traditional way, which in turn helps them gain a deeper knowledge of the subjects. The spelling checker is unable to teach them the correct spelling, resulting in a huge number of spelling errors on paper.

Since humans are not infallible, technology can be wrong in the same way. There are many issues such as server error and connection issues that will take a long time to fix, making learning difficult and slow, which can sometimes be frustrating for both students and teachers. Waste of time due to unnecessary problems is generally discouraged in schools or any educational institution where every moment of time is valued.With the acceleration of technology, the website owner is calling for their websites to rank higher in search engines so that they only focus on ranking and not the content they are. Many sources contain incorrect information that has been copied and pasted from other websites without verifying its accuracy. In this way, a student can receive deliberately false information on these resources. This can become a serious obstacle to their activities.

It is believed that due to all new technologies there may be a loss of communication skills and the ability of people to interact and communicate with each other. Many new 
technologies are designed for self-use and there are serious concerns about losing the interpersonal and collaborative skills that students typically develop in the classroom.

The latest and most advanced technology is very expensive. You have to pay for it to use it, which is difficult for most public schools because of the net cost. It is also difficult for parents because students get used to technology not at home! [5]

Introduction to the educational process of academic disciplines dedicated to block chain technology is one of the latest digital technology. One of the areas where block chains are actively integrated is the field of document storage and control. Here it is especially important to have guarantees that no one can manipulate the data and it will not be possible to overwrite it. Moreover, information about who added this or that record to the system is available to everyone. Blockchain is able to simplify the process of verifying education data, which is now used around the world. The only method of such verification can only be sending a request to an educational institution. The options for using the blockchain by the education system are not limited only to storing documents in a database. All the advantages of this technology can radically change the education system, for example, to promote online learning. The prevalence of online courses is constantly increasing, because they are cheaper and allow you to get knowledge from anywhere in the world where there is an Internet connection. And if you combine different courses in blocks, you can develop training areas in many narrowly focused specialties. In addition to all this, standards should be developed for the blockchain that will allow for the recognition of any diplomas and certificates anywhere in the world. Certificates and diplomas confirm the presence of certain skills and knowledge of the candidate. Storing data in one system allows you to distribute it between companies, creating a system of dynamic personnel search for a set of specialist skills for specific enterprises. In turn, this will create a demand for certain skills, which in turn sets trends for learning certain courses in real time. The candidate will see exactly what needs to be studied in order to get the desired position. [6] Educational organizations, adapting to the new trends of the labour market, will offer "dynamic blocks of courses", where the student chooses only what he needs for further professional growth. The education system is also not always able to provide up-to-date training programs, which sometimes become outdated even before graduates receive their diplomas. With the creation of a system that would allow you to see the requirements for specialists in real time, there would be an understanding of what changes in the education system should occur. Moreover, it would make it easier to find jobs and combat unemployment among educated people. Such a blockchain-based registry is necessary for universities, graduates, employers, and the education system. Blockchain in educational institutions opens up huge opportunities for its effective use. Today, a blockchain infrastructure focused on academic research and publications is already being developed, which will allow building an infrastructure that will automatically record data on new publications in the blockchain and store a constantly updated picture of the links between publications (links, citations), and this will solve the problems of stratification of scientific publications by the impact factor of a particular publication, the citation index. The blockchain infrastructure will solve the problem of recording information about the licensing and patenting of a particular intellectual property object. Blockchain in educational institutions is already widely used in foreign countries and opens up huge opportunities for its effective use. In Japan, Singapore, the United States, Hong Kong, Estonia, and the United Kingdom, information technology is actively implemented in all industries, and the Singapore education system actively uses online learning and is considered one of the best. In Japan today, blockchain platforms are widely used in the educational sphere. For the first time, the blockchain technology in education was officially applied in 2017. It was the University of Nicosia (Cyprus), which decided to modernize in this way, simplify the process of searching and storing any documents about the specialization (diploma, certificate, scientific work). It was the first 
university to accept the Bitcoin cryp to currency for tuition fees. The University has opened MOOCs (Massive open online Course), which are available for distance learning to students from more than 83 countries. [7]

\section{Discussion}

It is worth noting that the digitalization of education in Russia will soon create many problems in schools. There is a considerable gap between the provision of the technique used by the learner and the traditional teaching methods.

As a result, digitalization has both defenders and opponents of this phenomenon. So some officials believe that such solutions will help to choose a comfortable training program and an individual approach to each pupil, student. If the technology helps to better understand and remember the material, then it can be studied and implemented. Others are more skeptical about this, claiming that the digitalization of Russian education is fraught with serious problems. For example, that the digitalization of educational resources, training programs and other things will not correspond to the informatization of the educational process. This area requires a constant flow of breakthrough and proactive ideas and projects.

In turn, the above trends will affect all aspects of education, which also affects class work and the development of education in general. Future classroom activities will present something other than the mundane picture, like a teacher standing in front of his students at desks lined up in ideal rows. The introduction of innovative digital technologies will change both the form and methods of teaching and the environment itself.

\section{Conclusion}

In today's world, intelligent use of technology can improve education. Distance learning has many advantages. But the main thing will always be the teacher-student relationship, because it is between them that learning takes place. There is an essential need to study and analyze the features of digital translation, which we define as the translation of texts from one language into another using specialized computer programs. [8]

In order to implement all the ideas mentioned above, you need specialists - developers of the appropriate software. Blockchain technology is currently experiencing a real boom, but its further development and implementation faces a huge obstacle - the lack of human capital that is interested and trained. [9]

Technology can be a very effective tool, but it is not meant to replace the teacher. The idea is to create a flexible learning environment that encourages innovation. The resulting success of such efforts will depend on how technology is applied to maintain student engagement. It can be frustrating and time-consuming at first, but in the end, technology in education can pave the way for new experiences, new discoveries, and new ways of learning and working together.

\section{References}

1. S. Shelkovnikova, E. Krasnova, R. Avedova, 14th International Technology, Education and Development Conference, 9354-9357 (2020).doi:10.21125/inted.2020.2592

2. M. Zacharova, Pedagogical and pshycological world 6, 47 (2020).

3. A. Grigorjev, Risks of digitalization at schools. 
4. H. Kaur, International Journal of Applied Research https://fedena.com/blog/2020/10/advantages-and-disadvantages-of-onlinelearning.html

5. K. Courville, Technology and its use in Education: Present Roles and Future Prospects.

6. L. Lelu, Blockchain from A to Z. All about the technology of the decade (Eksmo, 2018).

7. S. Raval, Blockchain technology in action (Piter, 2017).

8. E. Krasnova, E. Laskina, O. Moisova, E. Velichko, SGEM 5, 3.4, 427-433 (2018).

9. D. Drescher, Fundamentals of blockchain: an introductory course for beginners in 25 small chapters (DMK Press, 2018).

10. P. Vinya, M. Casey, The Era of Cryptocurrencies. How bitcoin and blockchain are changing the world economic order (Publishing House Mann, Ivanov and Ferber, 2017).

11. A. Antonopoulo, Mastering Bitcoin. Programming of the blockchain (DMK Press, 2018).

12. T. Makarevich, I. Makarevich, Vestnik Moscow university Seria 1, 2, 86 (2020).

13. L. Latishev, N. Severova, Vestnik Bryansk university 1, 297 (2017). 